\title{
The Influence of Helminth Immune Regulation on COVID-19 Clinical Outcomes: Is it Beneficial or Detrimental?
}

\author{
Muluneh Ademe (iD) \\ Friehiwot Girma ${ }^{2}$ \\ 'Department of Microbiology, \\ Immunology and Parasitology, College of \\ Health Sciences, Addis Ababa University, \\ Addis Ababa, Ethiopia; ${ }^{2}$ Department of \\ Pediatrics and Child Health Nursing, \\ School of Health Sciences, College of \\ Medicine and Health Sciences, Bahir Dar \\ University, Bahir Dar, Ethiopia
}

\begin{abstract}
Immunologically, chronic worm infections prevent themselves from strong immune responses by skewing the host response towards a T helper 2 (Th2) type. The regulatory response initiated by helminth infections is supposed to temper responses to nonhelminth antigens including viral infections which will, in turn, alter the clinical outcomes of infections. In view of this, recent reports highlighted the possible negative associations of severe COVID-19 and helminth co-infections in helminth-endemic regions. As the pathology of COVID-19 is primarily mediated by an excessive immune response and subsequent cytokine storm, which contributes to the poor prognosis of COVID-19, helminth-driven immune modulation will hypothetically contribute to the less severe outcomes of COVID19. Nevertheless, emerging reports also stated that COVID-19 and helminth co-infections may have more hidden outcomes than predictable ones. Herein, the current knowledge on the interaction of COVID-19 and helminth co-infections will be discussed.
\end{abstract}

Keywords: SARS-CoV-2, worm co-infections, cytokine storm, Th2 response

\section{Introduction}

COVID-19 becomes the most serious global public health crises in modern times. ${ }^{1}$ However, the differences in the susceptibility to COVID-19 and the disease severity across nations continue to be a concern. Available reports showed that this new public health crisis has been most active in countries where helminth infections are rare. ${ }^{2}$ Although the number of cases and deaths is on the rise, the morbidity and mortality of COVID-19 in low-income countries has been lower than predicted. ${ }^{3,4}$ Data coming from the COVID-19 pandemics show that pre-existing chronic diseases might influence the clinical outcomes of COVID-19 infection. ${ }^{5}$ In view of this, recent reports drew attention to the associations between chronic helminth infection and COVID-19 disease severity in helminth-endemic regions. Yet, reports vary considerably and there is no common understanding of the interaction between these two disease conditions. In different reports, the possible beneficial and detrimental effects of COVID-19 and helminth co-infections have been shown. The aim of this review is, therefore, to summarize the current understanding on the interaction of COVID-19 and helminth co-infections. The potential influence of helminth co-infections on the clinical outcome of COVID-19 patients will be discussed. For this purpose, peerreviewed research articles, reviews and short communications by international organizations were reviewed. Search engines including PubMed Central, Scopus, and
Correspondence: Muluneh Ademe P.O. Box: 9086, Addis Ababa, Ethiopia Tel +25I 912634868

Fax +25I I 55I 3099

Email muluneh.ademe@aau.edu.et 
Google Scholar were used. In the search engines, we have used key words (phrases) including but not limited to COVID-19, Helminth infections, Immunomodulation, Immunopathology, Epidemiology, Interaction, and Clinical outcome. The search was restricted to English language.

\section{COVID-19}

Coronavirus disease 2019 (COVID-19) is caused by the novel betacoronavirus, now named severe acute respiratory syndrome coronavirus 2 (SARS-Cov-2). ${ }^{6,7}$ According to the phylogenetic diversity studies, SARS-Cov-2 and SARS-Cov share about $80 \%$ nucleotide sequence. SARSCov had been a cause of an epidemic in 2002/3 which affected 26 countries with about 8000 cases. ${ }^{8}$ The first COVID-19 cases have been reported from the Chinese city of Wuhan by the end of 2019. Since then, cases have started to be reported in different countries, and the disease was declared a pandemic by WHO in March 2020. COVID-19 has currently affected more than 216 countries with over 200 million cases. ${ }^{9,10}$ Indeed, the overall burden of COVID-19 might be higher than the reported case counts because only a fraction of infections is diagnosed and reported. In Europe and the United States (US), for instance, seroprevalence surveys have shown that the rate of prior exposure to SARS-CoV-2 exceeds the incidence of reported cases by approximately 10 -fold or more. ${ }^{11,12}$ The highest numbers of cases and deaths have been reported from the USA, Brazil, and India, however, Africa has a low number of COVID-19 cases and fatalities compared to other continents partly be due to limited testing capacity and delays in reporting confirmed cases. ${ }^{13,14}$ The sign and symptoms of COVID-19 vary from person to person. ${ }^{13}$ However, pneumonia and acute respiratory distress syndrome (ARDS) are among the serious clinical manifestations mainly in immunecompromised patients and elderly. ${ }^{6,15}$

\section{Helminth Infections}

Helminths are a class of neglected tropical diseases, which comprise roundworms, flatworms, tapeworms, and flukes. ${ }^{16}$ Schistosomiasis and soil-transmitted helminths (STHs) are the most common helminth infections worldwide. ${ }^{17,18}$ Globally, the burden of STHs was accounted to be above 3 million disability-adjusted life-years (DALYs). ${ }^{19}$ Infections with worms, or helminthiases, are the most common infectious diseases with disproportionately high prevalence rates in resource-poor settings. ${ }^{4}$ The human helminthiases exhibit a tremendous diversity of pathology.
Usually, a small worm burden has limited or no pathology and may be commensal to the host. ${ }^{17}$ However, heavy infection with parasitic worms can lead to serious complications including death. ${ }^{20,21}$ Helminthiases may cause lifethreatening chronic health conditions such as blindness (onchocerciasis), adult-onset epilepsy (Taenia solium infections), bladder cancer (schistosomiasis), and liver and bile duct cancer (trematodiases). ${ }^{22-24}$ In children, helminth infections may cause stunted growth and impaired cognitive development. ${ }^{25}$ Furthermore, infection with parasitic worms can increase host susceptibility to other co-infections. ${ }^{26}$

\section{Immune Regulation by Helminths}

Most helminth parasites are large, long-lived organisms, and mostly they are not able to replicate within their human host. Due to these features, antigenic variation and sequestration in specialized niches are not feasible for helminths to escape from the host defense. ${ }^{27}$ In this regard, helminths use a different strategy, immune regulation, to survive within the host. Immune regulation, in this case, refers to the capacity of helminths to limit the excessive host immune response directed toward themselves. During long-standing chronic infection, helminths elicit limited inflammation in invaded tissues and install an immunoregulatory environment that ensures their survival. ${ }^{18,27}$ This kind of relationship between worms and the host evolves to a reciprocal beneficial outcome. On the one hand, it helps helminths to remain unrecognized in human tissues and protects them from being eradicated. On the other hand, the host is protected from excessive immune responses that may result in organ damage. ${ }^{27,28}$ Helminth infections may restrain host immune responses through different mechanisms, including but not limited to suppression of Th1/Th2 response, manipulation of pattern recognition receptors (PRRs), stimulation of regulatory cells, and induction of apoptosis in immune cells. ${ }^{29-31}$

Immunoregulation during helminth infections is induced by helminth-derived products, which can be either parasite secretions, excretions, proteins, or extracellular vesicles that constantly interact with the host immune system. ${ }^{32}$ Immunoregulation by Echinococcus granulosus, for instance, was shown to be driven by the hydatid fluid and antigen $\mathrm{B}(\mathrm{AgB})$ which suppresses dendritic cells (DC) maturation and monocyte differentiation, resulting in reduced anti-parasite responses. ${ }^{33}$ During Trichuris suis infection, prostaglandin (PGE2) appears to impair TLR4-associated myeloid differentiation primary response 
protein 88 (MyD88) and the TIR-domain-containing adaptor-inducing interferon- $\beta$ (TRIF) signaling. ${ }^{34-36}$ Similarly, the phosphorylcholine-containing glycoprotein (ES-62) released by the filarial worm Acanthocheilonema viteae was described to mediate the regulatory response. ${ }^{37}$ Body fluid from adult Ascaris suum was also reported to induce hypo-responsiveness in human antigen-presenting cells (APCs) treated with Lipopolysaccharides (LPS) and modulate different human macrophage phenotypes. ${ }^{38,39}$

\section{Helminth and COVID- 19 Co-Infections}

It is well documented that the host-parasite interactions during worm infection cause the immune system to mount a type 2 response. $^{40}$ Type 2 responses will be followed by an increase in anti-inflammatory cytokines, eosinophils, regulatory T cells (Treg), and M2 macrophages. ${ }^{2,40,41}$ Being one of the powerful immune modulators, preexisting helminth infections may influence the clinical outcomes of COVID19. Nevertheless, helminth-induced immune regulation may result in both beneficial and detrimental outcomes.

\section{Beneficial Outcomes of Helminth and COVID-I 9 Co-Infections}

COVID-19 pathology is mediated by an overreaction of the host immune system (cytokine storm). ${ }^{42}$ An exacerbated systemic inflammatory response and the massive release of IL-1, IL-2, IL-7, G-CSF, IP-10, MCP-1, MIP$1 \mathrm{~A}$, and TNF $\alpha$ was observed in severe COVID-19 cases. $^{43}$ Data coming from the COVID-19 pandemics showed that people with pre-existing conditions such as chronic pulmonary diseases, ${ }^{44}$ cardiovascular diseases (CVD) ${ }^{45}$ renal diseases, ${ }^{46}$ and metabolic syndromes ${ }^{47,48}$ are at higher risk of severe disease and mortality when infected. These metabolic diseases are characterized by increased levels of proinflammatory cytokines. ${ }^{2}$ Helminth infections, on the other hand, are known to induce an immunotolerogenic state and modulate responses associated with inflammation. In this case, helminth-induced immunoregulation will help to modulate COVID-19-induced inflammation and the interaction of helminth and COVID-19 coinfections may perhaps be beneficial for the patient. The beneficial interactions during helminth co-infections have been shown in previous reports. As reviewed in, ${ }^{49}$ individuals with worm infections are less likely to have metabolic dysfunctions as compared to those without helminth infections. Rajamanickam and colleagues also reported that type 2 diabetes patients with concomitant helminth infections had reduced levels of proinflammatory cytokines and, this effect was reversed following treatment of the helminth infection. ${ }^{50}$ Furthermore, in a mice model by Rolot et al, prior exposure to Schistosoma mansoni eggs have shown a reduced disease severity of murid gammaherpesvirus 4 infection. ${ }^{51}$

Besides, a previous study on mice coinfected with Heligmosomoides polygyrus bakeri (H. polygyrus) and influenza virus showed a decreased lung consolidation possibly due to the immunosuppressive effect of H. polygyrus. ${ }^{52}$ In this regard, owing to helminths beneficial immunomodulatory effects shown on other infections, it may be feasible to propose a reduced risk of severe COVID-19 in patients with pre-existing helminth infections. $^{3,53}$

A recent data by Gebrecherkos et $\mathrm{a}^{53}$ from Ethiopia reported that $33.8 \%$ of COVID-19 patients had helminth co-infections with either Ascaris lumbricoides, Hymenolepis nana, or Schistosoma mansoni, and COVID-19 was less severe in those patients with preexisting helminth co-infections. Interestingly in the same study, COVID-19 patients with helminth co-infections were less likely to have non-communicable diseases (NCDs), including hypertension, cardiovascular diseases, and diabetes. ${ }^{53}$ Along the same lines, an ecological study by Ssebambulidde and colleagues also stated that the comparatively low COVID-19 cases/deaths in parasiteendemic areas might be due to immunomodulation induced by parasites. ${ }^{3}$ Bradbury et $\mathrm{al}^{54}$ in a recent commentary, offer the view that both helminths and SARSCoV-2 induce Th2 cytokines and the boosted type 2 cytokine responses could regulate the severe inflammatory responses during helminth and COVID-19 coinfection. Hays et $\mathrm{al}^{2}$ also believe that chronic worm infections may protect COVID-19 patients from the severe pathological responses. However, contrary to Bradbury et al report, Hays and colleagues suggested that anti-inflammatory cytokines (IL-4 and IL-10) associated with COVID-19 may not be pathological responses by the virus. Instead, it is a normal regulatory and tissue-repair response to viral-induced inflammation.

\section{Detrimental Outcomes of Helminth and COVID- 19 Co-Infections}

It does not often hold true that COVID-19 severity is lower in helminth-endemic regions. There are some 
helminth endemic areas that have been heavily affected by the pandemic. The Amerindian peoples of the Brazilian Amazon have a high burden of soil-transmitted helminth infection (45-95\%). ${ }^{55}$ However, this area was hugely affected by COVID-19 and the mortality rate was $250 \%$ higher than the rest of Brazil. ${ }^{56}$ The prevalence of soiltransmitted helminths in the rural communities of Venezuela is estimated to be $65 \%$; however, the area has been heavily affected by the COVID-19 pandemic. $^{57,58}$ These data show that COVID-19 and helminth coinfections may have more hidden outcomes than predictable ones. Indeed, previous pieces of evidence on viral infections reported that helminth co-infections may have detrimental clinical outcomes. On the one hand, the development of Treg and IL-10 production induced by helminths will impair the host immune responses, which in turn increases host susceptibility to microbial infections. ${ }^{59}$ On the other hand, gastrointestinal parasites may modulate the gut microbiome composition which will, in turn, cause systemic immunomodulation. ${ }^{41}$ In agreement with this, Reese et $\mathrm{al}^{60}$ and Osborne et $\mathrm{al}^{61}$ on their experimental studies on parasitic worm and virus co-infection in mice noted that the immunomodulatory role of helminths creates a favorable environment for the worms at the expense of antiviral immunity. In another study by Nayak and Kelley, increased mortality was observed in mice coinfected with Ascaris suum and influenza virus $(90 \%$ vs $30 \%){ }^{62}$ Taking these reports into account, COVID-19 and helminth co-infections may possibly have detrimental interactions. A systematic review by Abdoli et al $^{63}$ projected that preexisting helminth infections may suppress the efficient immune response against SARS-CoV-2 in the early stage of the infection, and thereby may increase the morbidity and mortality of COVID-19. Aside from their role of immune interaction, Paniz-Mondolfi et al showed a different perspective in which the increased severity and mortality of COVID-19 in helminth endemic areas may be attributed to the nutritional and metabolic compromises caused by worm infections. ${ }^{58}$

In parasite endemic regions, the management of helminth co-infections on COVID-19 patients remains controversial. Data on the outcome of treating helminth co-infections on COVID-19 patients is scarce. In fact, few reports showed the benefit of deworming in COVID-19 patients as it may decrease SARS-CoV-2 viral load and improve $\mathrm{CD} 8+\mathrm{T}$ cell in the lung microenvironment. ${ }^{64,65}$ Nevertheless, owing to the limited clinical evidence, it will be very difficult to reach such a conclusion that treating helminth co-infections is beneficial to COVID-19 patients.

\section{Conclusion}

COVID-19 and helminth co-infection may be a common phenomenon in low- and middle-income countries. However, their interaction is not yet well studied and understood enough. Data on pre-existing helminth and SARS-CoV-2 co-infection are just emerging. We are not certain whether treating helminth co-infections on COVID-19 patients will be beneficial or detrimental. There is therefore a need for prospective studies to examine the clinical and immunological perspectives of COVID-19 patients with helminth co-infections. The findings of such studies will be very important as they will determine the management of COVID-19 in areas where helminth infections are co-endemic. As the world is facing the third wave of the pandemic, understanding the interaction of helminth co-infections would clearly be of great interest.

\section{Abbreviations}

AAMs, alternatively activated macrophages; ARDS, acute respiratory distress syndrome; CD8, cluster of differentiation 8; COVID-19, coronavirus disease 2019; IL, interleukin; SARS-Cov-2, severe acute respiratory syndrome coronavirus 2; STH, soil transmitted helminths; Th1/Th2, T-helper cells; Treg, regulatory $\mathrm{T}$ cells.

\section{Author Contributions}

All authors made a significant contribution to the work reported, whether that is in the conception, study design, execution, acquisition of data, analysis and interpretation, or in all these areas; took part in drafting, revising or critically reviewing the article; gave final approval of the version to be published; have agreed on the journal to which the article has been submitted; and agree to be accountable for all aspects of the work.

\section{Funding}

The authors received no financial support.

\section{Disclosure}

The authors declare no conflicts of interest for this work.

\section{References}

1. Yang P, Wang X. COVID-19: a new challenge for human beings. Cell Mol Immunol. 2020;17(5):555-557. doi:10.1038/s41423-020-0407-x 
2. Hays R, Pierce D, Giacomin P, Loukas A, Bourke P, McDermott R. Helminth coinfection and covid-19: an alternate hypothesis. PLoS Negl Trop Dis. 2020;14(8):1-3. doi:10.1371/journal.pntd.0008628

3. Ssebambulidde K, Segawa I, Abuga KM, et al. Parasites and their protection against COVID-19- Ecology or Immunology? medRxiv. 2020. doi:10.1101/2020.05.11.20098053

4. Masaku J, Mutungi F, Gichuki PM, Okoyo C, Njomo DW, Njenga SM. High prevalence of helminths infection and associated risk factors among adults living in a rural setting, central Kenya: a cross-sectional study. Trop Med Health. 2017;45(1):1-9. doi:10.1186/ s41182-017-0055-8

5. Geng JS, Yu XL, Bao HN, et al. Chronic diseases as a predictor for severity and mortality of COVID-19: a systematic review with cumulative meta-analysis. Front Med. 2021;8(September):1-16. doi:10.3389/fmed.2021.588013

6. Lake MA. What we know so far: COVID-19 current clinical knowledge and research. Clin Med. 2020;20(2):124-127. doi:10.7861/ clinmed.2019-coron

7. Wang C, Horby PW, Hayden FG, Gao GF. A novel coronavirus outbreak of global health concern. Lancet. 2020;395 (10223):470-473. doi:10.1016/S0140-6736(20)30185-9

8. de Wit E, van Doremalen N, Falzarano D, Munster VJ. SARS and MERS: recent insights into emerging coronaviruses. Nat Rev Microbiol. 2016;14(8):523-534. doi:10.1038/nrmicro.2016.81

9. Cucinotta D, Vanelli M. WHO declares COVID-19 a pandemic. Acta Biomed. 2020;91(1):157-160.

10. World Health Organization. Coronavirus disease (COVID-19) weekly epidemiological update and weekly operational update [Internet]; 2021. Available from: https://www.who.int/emergencies/diseases/ novel-coronavirus-2019/situation-reports. Accessed October 19, 2021.

11. Stringhini S, Wisniak A, Piumatti G, et al. Seroprevalence of anti-SARS-CoV-2 IgG antibodies in Geneva, Switzerland (SEROCoV-POP): a population-based study. Lancet. 2020;396 (10247):313-319. doi:10.1016/S0140-6736(20)31304-0

12. Havers FP, Reed C, Lim T, et al. Seroprevalence of antibodies to SARS-CoV-2 in 10 sites in the United States, March 23-May 12, 2020. JAMA Intern Med. 2020;180(12):1576. doi:10.1001/ jamainternmed.2020.4130

13. Derbie A, Mekonnen D, Woldeamanuel Y, Abebe T. No TitWhy has Africa reported relatively few COVID-19 cases so far? A web-based survey. Ethiop J Heal Dev. 2020;34(4):313-316.

14. Dente MG, Resti CV, Declich S, Putoto G. The reported few cases and deaths of covid-19 epidemic in Africa are still data too questionable to reassure about the future of this continent. Front Public Heal. 2021;9:10-13.

15. Welker C, Huang J, Gil IJN, Ramakrishna H. Acute respiratory distress syndrome update, with coronavirus disease 2019 focus. J Cardiothorac Vasc Anesth. 2021. doi:10.1053/j.jvca.2021.02. 053

16. Brindley PJ, Mitreva M, Ghedin E, Lustigman S. Helminth genomics: the implications for human health. PLoS Negl Trop Dis. 2009;3 (10):e538. doi:10.1371/journal.pntd.0000538

17. Karin N, Miles JJ. Helminth immunomodulation in autoimmune disease. Front Immunol. 2017;8(April):453.

18. Gazzinelli-Guimaraes PH, Nutman TB. Helminth parasites and immune regulation. F1000Research. 2018;7:1685. doi:10.12688/ f1000research. 15596.1

19. Si H. Global, regional, and national disability-adjusted life-years (DALYs) for 333 diseases and injuries and healthy life expectancy (HALE) for 195 countries and territories, 1990-2016: a systematic analysis for the Global Burden of Disease Study 2016. Lancet. 2017;390(10100):1260-1344.

20. Hotez PJ, Brooker S, Bethony JM, Bottazzi ME, Loukas A, Xiao S. Hookworm infection. $N$ Engl J Med. 2004;351(8):799-807. doi:10.1056/NEJMra032492
21. Maizels RM, Yazdanbakhsh M. Immune regulation by helminth parasites: cellular and molecular mechanisms. Nat Rev Immunol. 2003;3(9):733-744. doi:10.1038/nri1183

22. Dixon MA, Braae UC, Winskill P, et al. Strategies for tackling Taenia solium taeniosis/cysticercosis: a systematic review and comparison of transmission models, including an assessment of the wider Taeniidae family transmission models. PLoS Negl Trop Dis. 2019;13(4): e0007301. doi:10.1371/journal.pntd.0007301

23. Mostafa MH, Sheweita SA, O'Connor PJ. Relationship between schistosomiasis and bladder cancer. Clin Microbiol Rev. 1999;12 (1):97-111.

24. Schluth CG, Standley CJ, Bansal S, Colin J. Mapping the human helminthiases: advances and gaps in neglected disease surveillance. MedRxiv. 2020;1-26. doi:10.1101/2020.10.30.20223529

25. Pabalan N, Singian E, Tabangay L, Jarjanazi H, Boivin MJ, Ezeamama AE. Soil-transmitted helminth infection, loss of education and cognitive impairment in school-aged children: a systematic review and meta-analysis. PLoS Negl Trop Dis. 2018;12(1): e0005523. doi:10.1371/journal.pntd.0005523

26. Mbabazi PS, Andan O, Fitzgerald DW, Chitsulo L, Engels D, Downs JA. Examining the relationship between urogenital schistosomiasis and HIV infection. PLoS Negl Trop Dis. 2011;5(12):e1396. doi:10.1371/journal.pntd.0001396

27. van Riet E, Hartgers FC, Yazdanbakhsh M. Chronic helminth infections induce immunomodulation: consequences and mechanisms. Immunobiology. 2007;212(6):475-490. doi:10.1016/j.imbio.2007.03.009

28. Allen JE, Maizels RM. Diversity and dialogue in immunity to helminths. Nat Rev Immunol. 2011;11(6):375-388. doi:10.1038/ nri2992

29. Finlay CM, Walsh KP, Mills KHG. Induction of regulatory cells by helminth parasites: exploitation for the treatment of inflammatory diseases. Immunol Rev. 2014;259(1):206-230. doi:10.1111/imr.12164

30. Zakeri A. Helminth-induced apoptosis: a silent strategy for immunosuppression. Parasitology. 2017;144(13):1663-1676. doi:10. 1017/S0031182017000841

31. Oliveira SC, Figueiredo BC, Cardoso LS, Carvalho EM. A double edged sword: schistosoma mansoni Sm29 regulates both Th1 and Th2 responses in inflammatory mucosal diseases. Mucosal Immunol. 2016;9(6):1366-1371. doi:10.1038/mi.2016.69

32. Zakeri A, Hansen EP, Andersen SD, Williams AR, Nejsum P. Immunomodulation by helminths: intracellular pathways and extracellular vesicles. Front Immunol. 2018;9:2349. doi:10.3389/fimmu. 2018.02349

33. Riganò $\mathrm{R}$, Buttari $\mathrm{B}$, Profumo $\mathrm{E}$, et al. Echinococcus granulosus antigen $\mathrm{B}$ impairs human dendritic cell differentiation and polarizes immature dendritic cell maturation towards a Th2 cell response. Infect Immun. 2007;75(4):1667-1678. doi:10.1128/IAI.01156-06

34. Klaver EJ, van der Pouw Kraan TCTM, Laan LC, et al. Trichuris suis soluble products induce Rab7b expression and limit TLR4 responses in human dendritic cells. Genes Immun. 2015;16(6):378-387. doi:10. 1038/gene.2015.18

35. Laan LC, Williams AR, Stavenhagen K, et al. The whipworm (Trichuris suis) secretes prostaglandin E2 to suppress proinflammatory properties in human dendritic cells. FASEB J off Publ Fed Am Soc Exp Biol. 2017;31(2):719-731.

36. Summan A, Nejsum P, Williams AR. Modulation of human dendritic cell activity by Giardia and helminth antigens. Parasite Immunol. 2018;40(5):e12525. doi:10.1111/pim.12525

37. Pineda MA, Eason RJ, Harnett MM, Harnett W. From the worm to the pill, the parasitic worm product ES-62 raises new horizons in the treatment of rheumatoid arthritis. Lupus. 2015;24(4-5):400-411. doi: $10.1177 / 0961203314560004$

38. Almeida S, Nejsum P, Williams AR. Modulation of human macrophage activity by Ascaris antigens is dependent on macrophage polarization state. Immunobiology. 2018;223(4-5):405-412. doi:10. 1016/j.imbio.2017.11.003 
39. Midttun HLE, Acevedo N, Skallerup P, et al. Ascaris suum infection downregulates inflammatory pathways in the pig intestine in vivo and in human dendritic cells in vitro. J Infect Dis. 2018;217(2):310-319. doi:10.1093/infdis/jix 585

40. Harris NL, Loke P. Recent advances in type-2-cell-mediated immunity: insights from helminth infection. Immunity. 2017;47 (6):1024-1036. doi:10.1016/j.immuni.2017.11.015

41. Brosschot TP, Reynolds LA. The impact of a helminth-modified microbiome on host immunity. Mucosal Immunol. 2018;11 (4):1039-1046. doi:10.1038/s41385-018-0008-5

42. Kruse RL. Therapeutic strategies in an outbreak scenario to treat the novel coronavirus originating in Wuhan, China. F1000Research. 2020;9:72. doi:10.12688/f1000research.22211.2

43. Huang C, Wang Y, Li X, et al. Clinical features of patients infected with 2019 novel coronavirus in Wuhan, China. Lancet. 2020;395 (10223):497-506. doi:10.1016/S0140-6736(20)30183-5

44. Çakır Edis E. Chronic pulmonary diseases and COVID-19. Turkish Thorac J. 2020;21(5):345-349. doi:10.5152/TurkThoracJ.2020.20091

45. Nishiga M, Wang DW, Han Y, Lewis DB, Wu JC. COVID-19 and cardiovascular disease: from basic mechanisms to clinical perspectives. Nat Rev Cardiol. 2020;17(9):543-558. doi:10.1038/ s41569-020-0413-9

46. Bitencourt L, Pedrosa AL, de Brito SBCS, et al. COVID-19 and renal diseases: an update. Curr Drug Targets. 2021;22(1):52-67. doi:10. 2174/1389450121999201013151300

47. Yanai H. Metabolic Syndrome and COVID-19. Cardiol Res. 2020;11 (6):360-365. doi:10.14740/cr1181

48. Bornstein SR, Rubino F, Ludwig B, et al. Consequences of the COVID-19 pandemic for patients with metabolic diseases. Nat Metab. 2021;Mar(3):289-292. doi:10.1038/s42255-021-00358-y

49. Tracey EF, McDermott RA, McDonald MI. Do worms protect against the metabolic syndrome? A systematic review and meta-analysis. Diabetes Res Clin Pract. 2016;120:209-220. doi:10.1016/j.diabres.2016.08.014

50. Rajamanickam A, Munisankar S, Dolla C, et al. Helminth infection modulates systemic pro-inflammatory cytokines and chemokines implicated in type 2 diabetes mellitus pathogenesis. PLoS Negl Trop Dis. 2020;14(3):e0008101. doi:10.1371/journal.pntd.0008101

51. Rolot M, Dougall AM, Chetty A, et al. Helminth-induced IL-4 expands bystander memory $\mathrm{CD} 8(+) \mathrm{T}$ cells for early control of viral infection. Nat Commun. 2018;9(1):4516. doi:10.1038/s41467-018-06978-5

52. Chowaniec W, Wescott RB, Congdon LL. Interaction of Nematospiroides dubius and influenza virus in mice. Exp Parasitol. 1972;32(1):33-44. doi:10.1016/0014-4894(72)90007-0
53. Gebrecherkos T, Gessesse Z, Kebede Y, Gebreegzabher A, Wit TRD, Wolday D. Effect of co-infection with parasites on severity of COVID-19. medRxiv. 2021;267:1-15.

54. Bradbury RS, Piedrafita D, Greenhill A, Mahanty S. Will helminth co-infection modulate COVID-19 severity in endemic regions? Nat Rev Immunol. 2020;20(6):342. doi:10.1038/s41577-020-0330-5

55. Oliveira RA, Gurgel-gonçalves R, Machado ER. Intestinal parasites in two indigenous ethnic groups in northwestern Amazonia. Acta Amaz. 2016;46(3):241-246. doi:10.1590/1809-4392201505883

56. Ramírez JD, Sordillo EM, Gotuzzo E, et al. SARS-CoV-2 in the Amazon region: a harbinger of doom for Amerindians. PLoS Negl Trop Dis. 2020;14(10):e0008686. doi:10.1371/journal.pntd.0008686

57. Nastasi-Miranda J. Prevalence of intestinal parasites in educational units from Ciudad Bolı'var, Venezuela. Rev Cuid. 2015;6 (2):1077-1084. doi:10.15649/cuidarte.v6i2.181

58. Paniz-Mondolfi AE, Ramírez JD, Delgado-Noguera LA, RodriguezMorales AJ, Sordillo EM. Covid-19 and helminth infection: beyond the th1/th2 paradigm. PLoS Negl Trop Dis. 2021;15(5):10-12. doi:10.1371/journal.pntd.0009402

59. Su C, Cao Y, Zhang M, et al. Helminth infection impairs autophagy-mediated killing of bacterial enteropathogens by macrophages. J Immunol. 2012;189(3):1459-1466. doi:10.4049/ jimmunol.1200484

60. Reese TA, Wakeman BS, Choi HS, et al. Helminth infection reactivates latent $\gamma$-herpesvirus via cytokine competition at a viral promoter. Science. 2014;345(6196):573-577. doi:10.1126/science.1254517

61. Osborne LC, Monticelli LA, Nice TJ, et al. Virus-helminth coinfection reveals a microbiota-independent mechanism of immunomodulation. Science (80-). 2014;345(6196):578-582. doi:10.1126/science.1256942

62. Nayak D, Kelley G. Synergistic effect of Ascaris migration and influenza infection in mice. $J$ Parasitol. 1965;51(2):297-298. doi: $10.2307 / 3276103$

63. Abdoli A. Helminths and COVID-19 co-infections: a neglected critical challenge. ACS Pharmacol Transl Sci. 2020;3:1039-1041.

64. Chacin-Bonilla L, Chacón-Fonseca N, Rodriguez-Morales AJ. Emerging issues in COVID-19 vaccination in tropical areas: impact of the immune response against helminths in endemic areas. Travel Med Infect Dis. 2021;42:2.

65. Liao M, Liu Y, Yuan J, et al. Single-cell landscape of bronchoalveolar immune cells in patients with COVID-19. Nat Med. 2020;26 (6):842-844. doi:10.1038/s41591-020-0901-9
Infection and Drug Resistance

\section{Publish your work in this journal}

Infection and Drug Resistance is an international, peer-reviewed openaccess journal that focuses on the optimal treatment of infection (bacterial, fungal and viral) and the development and institution of preventive strategies to minimize the development and spread of resistance. The journal is specifically concerned with the epidemiology of antibiotic resistance and the mechanisms of resistance development and diffusion in both hospitals and the community. The manuscript management system is completely online and includes a very quick and fair peerreview system, which is all easy to use. Visit http://www.dovepress.com/ testimonials.php to read real quotes from published authors. 